\title{
Carbonation resistance of recycled aggregate concrete
}

\section{Andreas Leemann (1), Roman Loser (1)}

(1) Empa, Laboratory for Concrete \& Construction Chemistry, CH 8600, Dübendorf, Switzerland

andreas.leemann@empa.ch

\begin{abstract}
The environmental impact of concrete production can be decreased by the use of cement with reduced clinker content or the reuse of concrete waste provided by the demolition of buildings in recycled aggregate concrete (RC). In this study, the carbonation resistance of RC is investigated in order to clarify the influence of recycled aggregate percentage, moisture state of the aggregates prior to concrete production and type of cement used. RC with two different replacement levels of natural aggregates is produced using three different blended cements and compared to reference concrete mixtures produced with natural aggregates.

The carbonation resistance of $\mathrm{RC}$ can be decreased by particles of recycled aggregate that are either very porous or already carbonated before concrete production. There were no systematic differences in compressive strength and carbonation resistance between dry and pre-saturated aggregates. The carbonation resistance at a given compressive strength decreases with decreasing clinker content of the cement.
\end{abstract}

Keywords: recycled aggregate concrete, blended cement, carbonation

\section{Introduction}

There are different strategies to reduce the environmental impact of concrete production. One possibility is the use of cement with reduced clinker content. Another is the reuse of concrete waste provided by the demolition of buildings in recycled aggregate concrete (RC). In the Swiss building industry, these two approaches are combined in concrete used for house building. Blended cements typically contain up to 20 or 35 mass- $\%$ of mineral additions corresponding to CEM II/A and CEM II/B according to [1]. Mineral additions include limestone powder as the most frequently used solution, burnt oil shale, fly ash and slag. Recycled aggregates (RA) mainly consist of recycled concrete aggregates for classified concrete types with a lower share of recycled mixed rubble. The amount of natural sand and gravel substituted with RA depends on the targeted concrete quality. $97 \%$ of the Swiss concrete production is represented by concrete type A (minimum cement content of $280 \mathrm{~kg} / \mathrm{m}^{3}$ and maximum water-to-cement-ratio (w/c) of 0.65 ), concrete type B (minimum cement content of $280 \mathrm{~kg} / \mathrm{m}^{3}$ and maximum $\mathrm{w} / \mathrm{c}$ of 0.60 ) and concrete type $C$ (minimum cement content of $300 \mathrm{~kg} / \mathrm{m}^{3}$ and maximum w/c of 0.50 ) [2]. The majority of RA is used in these concrete classes with a level of substitution typically between 25 and 50 mass-\%. A higher degree of substitution is easily possible from a technical point of view, but the increased cement content and increased dosage of superplasticizer required make such solutions economically less attractive.

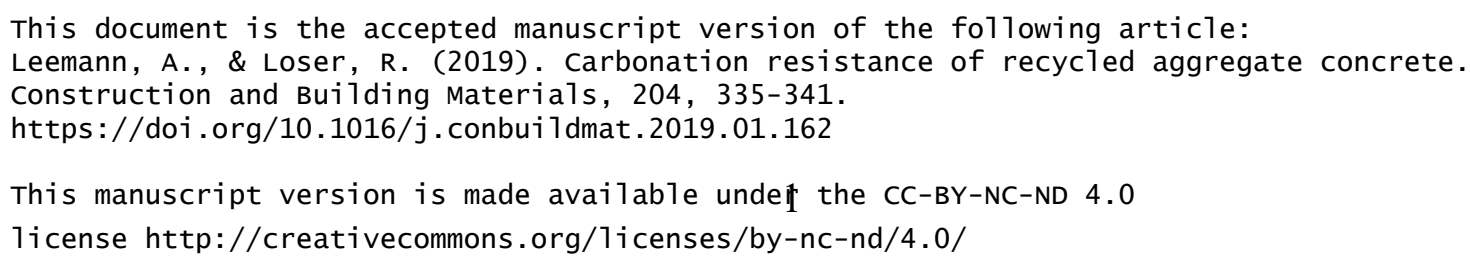


The production of $\mathrm{RC}$ is an established technique in Switzerland nowadays. This was made possible by owners requesting $\mathrm{RC}$ for specific projects, by innovative contractors and by simultaneously conducted research projects $[3,4]$. Based on the results of various research projects a guideline was published [5] providing information to civil engineers. The emphasis of research so far has clearly been on the mechanical [6-14] and time-dependent visco-elastic properties of the concrete [15-19]. However, carbonation of RC may be an issue. This issue has not received a lot of attention in literature. Moreover, carbonation is often not the main focus of attention these papers and is covered only marginally [20-26]. The conclusions on the impact of RA on carbonation resistance of concrete are sometimes contradicting and sometimes unclear, as comparisons are often drawn based only on one parameter, like w/c or compressive strength. Silva et al. [27] summarized the data available on carbonation of RC. Although carbonation resistance increases with increasing levels of NA substitution with RA [24,26,27], this seems mainly to be an effect of the increasing water demand and resulting increase in w/c. The ratio between compressive strength and carbonation coefficient $\mathrm{K}$ is similar for $\mathrm{RC}$ and concrete produced with NA [23,24,27,28]. Consequently, it is concluded that RC is suitable for the use in reinforced concrete structures [27].

In this study, the impact of recycled aggregate percentage, moisture state of the aggregates prior to concrete production and type of cement on the carbonation resistance of RC is investigated. The produced RC represents the typical composition used in the Swiss market. Two different replacement levels of natural aggregates (NA) and three different blended cements are used. The RA is provided by two different industrial sources. In one series of concrete mixtures, aggregates are used in dry state and in the other series they are used in pre-saturated condition. Bulk density and water absorption of the aggregates and compressive strength, oxygen diffusion, accelerated and natural carbonation of the concrete are determined. As such, this study should provide new insights on the effect of moisture content of RA on carbonation resistance of RC produced with blended cements and different replacement levels of NA. Moreover, it will show if accelerated carbonation of RC provides a reasonable assessment of carbonation in natural conditions.

\section{Materials and methods}

\subsection{Materials}

The cements used for concrete production (Table 1) were CEM II/A-LL (containing approximately 15 mass- $\%$ of limestone powder), CEM II/B-M (T-LL) (containing approximately 15 mass- $\%$ of limestone powder and 15 mass- $\%$ of burnt oil shale) and CEM III/B (containing a minimum of 66 mass- $\%$ of slag) according to [1]. As it is typical for large parts of Switzerland, well rounded river sand and gravel were used as NA (0-4 mm: 35 mass\%, 4-8 mm: 16 mass-\%, 8-16 mm: 17 mass-\%, 16-32 mm: 32 mass-\%) (Figure 1). The water absorption of the NA with the given grain size distribution was 0.5 mass- $\%$ and its oven-dried particle density $2650 \mathrm{~kg} / \mathrm{m}^{3}$ [29]. Two different RA from two industrial plants were used. Both RA consist of crushed concrete.

RA-1 was delivered in the same four grain size fraction as stated for the NA above (Figure 1). RA-2 was delivered in grain size of 0-16 mm. The sieve curve shows an amount of 38.5 mass$\%$ of $0-4 \mathrm{~mm}, 21.9$ mass- $\%$ of $4-8 \mathrm{~mm}$ and 39.6 mass- $\%$ of $8-16 \mathrm{~mm}$ (Figure 1 ). Particle density 
and water absorption of the two RA are given in Table 2 . The aggregates were stored at $20{ }^{\circ} \mathrm{C}$ and $70 \%$ relative humidity $(\mathrm{RH})$ before concrete production. Their moisture content as determined by oven drying to constant mass at $110{ }^{\circ} \mathrm{C}$ was taken into account in the concrete mix design. The aggregates stored in this condition were designated as "dry" in Table 3 . The aggregates designated as "saturated" in Table 3 were placed in the concrete mixer (rotating tool and counter-rotating pan) and a specific amount of water was added to them with the mixer turned on. The amount of water added corresponded to the water absorption as given in Table 2 minus the moisture content of the aggregates in the stated storing conditions. In the next step, cement was added into the mixer and after $30 \mathrm{~s}$ of mixing the water was added. The superplasticizer was added with the last $10 \%$ of water stored in a separate container.

Four concrete mixtures were produced with NA as reference (REF 01-04). The substitution of NA with RA in the RC was either 25 or 50 mass- $\%$. The difference in apparent particle density between NA and RA was taken into account in the mix design. Higher levels of replacement than 25 and 50 mass- $\%$ are easy to produce technically, but they are not economical as the required amount of cement and superplasticizer increase.

Concrete types $\mathrm{A}, \mathrm{B}$ and $\mathrm{C}$ were produced corresponding to the compressive strength classes of C20/25, C25/30 and C30/37, respectively [2]. Because of the lower loose bulk density and higher amount of voids of the RA compared to the NA the cement content was increased by 10$15 \mathrm{~kg} / \mathrm{m}^{3}$ in the RC mixtures resulting in a higher cement paste volume. This made it possible to fill the voids between the aggregates and produce a concrete with good workability. One concrete mixture (RC-07) was produced twice to assess reproducibility.

The w/c is given as two numbers representing the total water in the concrete $\left(w_{\text {total }} / c\right)$ and the total water minus water absorption of the aggregates as shown in Table $2\left(w_{E N} / c\right)$.

One important point in the production of $\mathrm{RC}$ has to be highlighted here. When the aggregates are added dry, they absorb water leading to a volume reduction of the concrete and a change of its bulk density. The later leads to a large difference between the calculated bulk density and the density as measured on the fresh concrete. Therefore, an empiric value of water absorbed during mixing is taken into account in the mix design. This value corresponds to about one third of the water absorption shown in Table 2. It has to be added to the volume of the concrete in the mix design calculation. For example, if a water absorption by the aggregates of $151 / \mathrm{m}^{3}$ is expected during mixing, the mix design calculation has to be done with a total volume of the concrete of 1015 instead of 1000 litres. If the calculated and the measured bulk density are within about $\pm 30 \mathrm{~kg} / \mathrm{m}^{3}$, the mix design can be regarded as sufficiently accurate. An air void content of 2.0 volume- $\%$ was assumed in the case of the concrete mixtures in Table 3 and the water absorption was calculated as described above. The average calculated bulk density was $21 \mathrm{~kg} / \mathrm{m}^{3}$ lower than the measured, with a slightly lower average air void content in the produced concrete than assumed (1.8 volume- $\%$, Table 4 ). If the calculated bulk density is corrected for the difference in air void content, the difference is reduced to $16 \mathrm{~kg} / \mathrm{m}^{3}$. This clearly indicates that the determined values for the oven-dried particle density and the assumed amount of water adsorbed by the aggregates during concrete production were accurate. 
Three cubes (150 X $150 \times 150 \mathrm{~mm}^{3}$ ) were produced for compressive strength, another two for oxygen diffusion and three prisms $\left(120 \times 120 \times 360 \mathrm{~mm}^{3}\right)$ for the determination of the carbonation depth. For measuring oxygen diffusion three cores $(\varnothing 100 \mathrm{~mm}$, height of $50 \mathrm{~mm})$ were extracted from two cubes at the age of 28 days.

\subsection{Methods}

The compressive strength of the the concrete cubes was measured according to EN 12390-3 [30].

The carbonation coefficient $K_{A C C}$ was determined according to SN 505 262/1 [31] and as described in [32-34]. The samples were demoulded after 24 hours, cured in water for two days and stored in climatic chamber at $20{ }^{\circ} \mathrm{C}$ and $57 \% \mathrm{RH}$ afterwards. At an age of 28 days they were placed in the carbonation chamber at a $\mathrm{CO}_{2}$ concentration of $4 \%$ and a $\mathrm{RH}$ of $57 \%$ for a duration of 63 days. Carbonation depth was determined at the start of exposure and after 7, 28 and 63 days. A validation of the accelerated test with natural carbonation is presented in $[32,33]$. The samples used for natural exposure were conditioned in the same way as the samples used for accelerated carbonation until an age of 28 days. At this age they were placed outdoors to carbonate in natural conditions. The carbonation coefficient $K_{N}$ of the concrete exposed outdoors was determined after an exposure of one year. The determination of the carbonation depth requires five equally-spaced measurements per side of the split-off prism slab, totalling 20 measurements per age and concrete mixture. RA has two specific properties compared to NA that can affect carbonation depth. First, RA carbonated before being used as concrete aggregate lead to a local increase of the carbonation depth. Secondly, porous RA may carbonate considerably faster than the cement paste of the new concrete, causing a local increase of the carbonation depth as well (Figure 2). The opposite case, where a RA particles carbonate slower than the cement paste of the new concrete, is seldom observed (Figure 3). The carbonation depth of the concrete exposed to accelerated carbonation was measured in two different ways in order to assess the impact of such RA. In the first measurement, the depth of the carbonation front in the cement paste of the newly-produced concrete mixture was determined neglecting local changes of carbonation depth due to RA. In the second measurement, the locally increased carbonation depth caused by RA was taken into account, as required by SN 505 262/1.

The carbonation coefficient $K$ was calculated using the regression of the carbonation depth as a function of the square root of time (equation 1):

$K=\frac{\left(d_{K}-A\right)}{\sqrt{t}}$

where $K$ is the carbonation coefficient in $\mathrm{mm} / \sqrt{\mathrm{y}}_{\mathrm{y}}, d_{K}$ the carbonation depth in $\mathrm{mm}, A$ the initial carbonation depth in $\mathrm{mm}$ after curing and $t$ the time in years.

Starting at 28 days, the three cores (diameter of $100 \mathrm{~mm}$, height of $50 \mathrm{~mm}$ ) tested per concrete mixture were first conditioned at $20^{\circ}$ and $35 \% \mathrm{RH}$ for 7 days before being dried in an oven at $50{ }^{\circ} \mathrm{C}$ for another 7 days. The oxygen diffusion coefficient $D_{O}$ was determined as described in [35-37] on. An oxygen flow was applied on one side of the cores and a nitrogen flow on the other side, with identical gas pressure on both sides. The oxygen content in the nitrogen flow 
was measured until steady-state conditions were reached. The oxygen diffusion coefficient was calculated according to [35].

\section{Results}

\subsection{Summary}

The summarized results are shown in Table 4.

\subsection{Compressive strength}

The compressive strength of the RC is significantly higher on average than the one of the REF at a given $\mathrm{w} / \mathrm{c}$, if the total water content is considered (Figure 4A). Assuming completely water saturated aggregates, the ratio is the same for both types of concrete at $w / c \geq 0.43$ (Figure 4B). At $w / c \leq 0.42$, the ratio between compressive strength and $w / c$ changes, with considerably higher values for the RC, mainly the one produced with RA-2. No net effect of the preconditioning of the aggregates was observable: the use of dry and pre-saturated aggregates results in practically identical 2 days and 28 days compressive strength (Figure 5).

\subsection{Carbonation resistance}

RC produced with CEM II/A-LL shows about the same relation between compressive strength and carbonation coefficient $K_{A C C}$ as REF (Figure 6A). No difference can be seen between RC with a replacement level of 25 and 50 mass- $\%$, respectively. The two RC produced with CEM II/B-M have a slightly increased carbonation coefficient $K_{A C C}$ compared to the concrete produced with CEM II/A-LL, while the values are significantly increased in the case of RC produced with CEM III/B. The carbonation coefficient $K_{A C C^{*}}$ taking into account locally increased carbonation depth due to carbonated RA is slightly increased (Figure 6B) by a mean value of $10 \%$. Like in the case of compressive strength, there is no systematic difference in the carbonation coefficient $K_{A C C}$ of the concrete with pre-saturated aggregates compared to one produced with dry aggregates (Figure 7). There is a reasonable correlation $\left(\mathrm{R}^{2}=0.80\right)$ between the accelerated and natural carbonation in sheltered conditions (Figure 8A). The correlation is worse $\left(\mathrm{R}^{2}=0.66\right)$ in the case of natural carbonation in unsheltered conditions (Figure $\left.8 \mathrm{~B}\right)$. None of the carbonation coefficients determined under different boundary conditions shows a correlation with oxygen diffusion coefficient $D_{O}$ (Table 4).

\section{Discussion \\ 4.1 Compressive strength}

The higher strength of RC (Figure 4A) is a result of the higher water absorption of RA, decreasing the effective $\mathrm{w} / \mathrm{c}$ of the cement paste. The $w_{E N} / c$ is a better parameter to assess compressive strength of RC than the $w_{\text {total }} / c$ (Figure 4B). The exaggerated non-linear strength increase at low w/c is partly caused by the fact that the relative amount of the total water absorbed by RA compared to NA increases with decreasing wEN/c (Figure 9) The especially pronounced strength increase with decreasing $w_{E N} / c$ of RA-2 at w/c $<0.43$ may be attributable to the high amount of fines in this specific aggregate. Based on these results, it is suggested that compressive strength and not $\mathrm{w} / \mathrm{c}$ is a used as the main parameter for comparing the properties of RC and with the ones of concrete produced with NA. 
The matching 2 and 28 day compressive strength of the concrete produced with pre-saturated and the dry aggregates give information about the water absorption of the aggregates. The amount of water available for hydration is the same, independently of the moisture state of the aggregates at the time of concrete production. This indicates that the water is adsorbed by the dry aggregates until hydration starts and is redistributed in the same way as in the case of presaturated aggregates, when RH decreases due to ongoing hydration. As such, RA behaves in a similar way like lightweight aggregates or superabsorbent polymers [38-40].

\subsection{Carbonation resistance}

Although single particles of RA that are either porous or already carbonated at the time of concrete production can lead to local increase of carbonation depth, the impact on the carbonation coefficient $K_{A C C}$ is not significant with an increase of $10 \%$ at a given compressive strength. Consequently, there is no systematic difference of carbonation coefficient $K$ and the replacement level of RA. This agrees with the findings of several studies when carbonation is compared to compressive strength $[23,24,27,28]$. In contrast to this, an increase of carbonation coefficient $K$ with increasing replacement level of $\mathrm{Na}$ with RA has also been reported [20,41]. Here, the study by Pedro et al. [28] is of special interest, as high performance concrete with a compressive strength of about $80 \mathrm{MPA}$ was studied. When the quality of the cement paste in the new concrete is considerably better than the one in the RA used, an increase of carbonation coefficient $K$ with increasing replacement level of NA seems inevitable. This likely contributes the fact that the carbonation coefficient $K$ of RC produced with CEM II/A-LL and a compressive strength above $45 \mathrm{MPa}$ is not decreasing more (Figure 6). However, RC curing generally has more significant influence on carbonation resistance than replacement level of NA [42].

The increase of the carbonation coefficient $K$ in the concrete produced with CEM II/B-M and CEM III/B is directly linked to the lower clinker content compared to CEM II/A-LL and the decreased $\mathrm{CO}_{2}$ buffer capacity in $[32,33]$. Consequently, the carbonation resistance of $\mathrm{RC}$ deceases as well, when cement is replaced with mineral additions like fly ash or silica fume containing no little or no $\mathrm{CaO}[23,28,43]$. As such, compressive strength can only be used as a control factor for carbonation resistance within a group of concrete produced with the same binder type.

The low w/c needed for concrete produced with CEM III/B to result in a carbonation coefficient $K_{A C C}$ below the limit value leads to a much higher compressive strength than required for the strength class $\mathrm{C} 30 / 37$.

The same carbonation coefficient $K_{A C C}$ of concrete produced with dry and pre-saturated aggregates indicates no measureable effect of water absorption on hydration, as discussed above.

The use of accelerated carbonation to assess the carbonation resistance of concrete exposed to natural conditions is reasonable. However, some restrictions have to be made in the case of natural carbonation in unsheltered outdoor exposure. Here, the concrete produced with CEM III/B displays a lower carbonation coefficient $K_{N, U S}$ than expected based on accelerated carbonation. This behaviour was already observed in [32], but not in [33]. It seems that the composition of the used slag plays a role, as it may lead to a specific behaviour in regard to 
capillary condensation, capillary suction and drying. Omitting the concrete produced with CEM III/B the correlation between carbonation coefficients $K_{A C C}$ and $K_{N, U S}$ improves from $\mathrm{R}^{2}=0.66$ to $\mathrm{R}^{2}=0.83$.

\section{Conclusions}

RC was produced using two different RA at varying amounts. Its carbonation resistance was determined in accelerated and natural conditions. Concrete produced with natural aggregates was used as reference (REF).

- The effect of water absorption on concrete volume has to be taken into account in concrete mix design to ensure a good agreement between calculated and effective bulk density.

- Water absorption of RA has a significant impact on compressive strength. Therefore wEN/c should be used to compare properties of concrete produced with aggregates of varying water absorption.

- No systematic difference in compressive strength and carbonation resistance between concrete produced with dry and pre-saturated aggregates was observed.

- The carbonation coefficient $K_{A C C}$ of RC produced with CEM II/A-LL is slightly increased by approximately $10 \%$ compared to REF produced with the same cement type at the same compressive strength due to local increases of carbonation depth caused by porous RA or RA already carbonated before concrete production.

- An increase of replacement level of NA from 25 to 50 mass- $\%$ did not increase the carbonation coefficient $K$ for a give compressive strength.

- Using cement with reduced clinker content leads to a slight (CEM II/B-M) and a significant (CEM III/B) increase of carbonation coefficient $K_{A C C}$ at a specific compressive strength due to the decreased $\mathrm{CO}_{2}$ buffer capacity.

- The low w/c required in the case of concrete produced with CEM III/B to fulfil the required limit values for carbonation resistance result in too high compressive strength for housebuilding and requires a very high cement content thereby increasing costs.

- Accelerated carbonation allows a reasonable assessment of carbonation in sheltered conditions, but shows a worse correlation with carbonation in unsheltered conditions. The latter is mainly attributable to the relatively low carbonation coefficients $K_{N, U S}$ of concrete produced with CEM III/B.

\section{Acknowledgements}

The authors would like to thank cemsuisse for financing the study and Pietro Lura for reviewing the manuscript.

\section{References}

[1] EN 197-1, Cement. Composition, specifications and conformity criteria for common cements, CEN, Brussels (2011).

[2] SN EN 206, Concrete. Specification, performance, production and conformity, National Appendix, SIA, Zürich, Switzerland (2013) (in French and German).

[3] C. Hoffmann, S. Schubert, A. Leemann, M. Motavalli, Recycled concrete and mixed rubble as aggregates: Influence of variations in composition on the concrete properties and their use as structural material, Constr. Build. Mater. 35 (2012) 701-709. 
[4] S. Schubert, C. Hoffmann, A. Leemann, K. Moser, M. Motavalli, Recycled aggregate concrete: experimental shear resistance of slabs without shear reinforcement, Eng. Struct. 41 (2012) 490-497.

[5] SIA 2030 - Recycling Concrete, SIA, Zürich, Switzerland (2010) (in French and German).

[6] I.B. Topcu, Physical and mechanical properties of concretes produced with waste concrete, Cem. Concr. Res. 27 (1997) 1817-1823.

[7] J. Xiao, J. Li, C. Zhang, Mechanical properties of recycled aggregate concrete under uniaxial loading, Cem. Concr. Res. 35 (2005) 1187-1194.

[8] J.Z. Xiao, J.B. Li, C. Zhang, On relationships between the mechanical properties of recycled aggregate concrete: an overview, Mater. Struct. 39 (2006) 655-664.

[9] K. Rahal, Mechanical properties of concrete with recycled coarse aggregate, Build. Environ. 42 (2007) 407-415.

[10] M. Etxeberria, E. Vázquez, A. Marí, M. Barra, Influence of amount of recycled coarse aggregates and production process on properties of recycled aggregate concrete, Cem. Concr. Res. 37 (2007) 735-742.

[11] A.E.B. Cabral, V. Schalch, D.C.C. Dal Molin, J.L.D. Ribeiro, Mechanical properties modeling of recycled aggregate concrete, Constr. Build. Mater. 24 (2010) 421-430.

[12] Xiao, J., Huang, Y., Yang, J., \& Zhang, C. Mechanical properties of confined recycled aggregate concrete under axial compression, Constr. Build. Mater. 26 (2012) 591-603.

[13] K. McNeil, T.H.K. Kang, Recycled concrete aggregates: A review, Int. J. Concr. Struct. Mater. 7 (2013) 61-69.

[14] M. Bravo, J. de Brito, J. Pontes, L. Evangelista, Mechanical performance of concrete made with aggregates from construction and demolition waste recycling plants, J. Clean. Prod. 99 (2015) 59-74.

[15] J.M. Gomez-Soberon, Relationship between gas adsorption and the shrinkage and creep of recycled aggregate concrete, Cem. Concr. Aggr. 25 (2003) 1-7.

[16] A. Domingo-Cabo, C. Lázaro, F. López-Gayarre, M.A. Serrano-López, P. Serna, J.O. Castaño-Tabares, Creep and shrinkage of recycled aggregate concrete, Constr. Build. Mater. 23 (2009) 2545-2553.

[17] A. Domingo, C. Lázaro, F.L. Gayarre, M.A. Serrano, C. Lopez-Colina, Long term deformations by creep and shrinkage in recycled aggregate concrete, Mater. Struct. 43 (2010) 1147-1160.

[18] V. Corinaldesi, Mechanical and elastic behaviour of concretes made of recycled-concrete coarse aggregates, Constr. Build. Mater. 24 (2010) 1616-1620.

[19] G. Fathifazl, A.G. Razaqpur, O.B. Isgor, A. Abbas, B. Fournier, S. Foo, Creep and drying shrinkage characteristics of concrete produced with coarse recycled concrete aggregate, Cem. Concr. Comp. 33 (2011) 1026-1037.

[20] N. Otsuki, S. I. Miyazato, W. Yodsudjai, Influence of recycled aggregate on interfacial transition zone, strength, chloride penetration and carbonation of concrete, J. Mater. Civ. Eng. 15 (2003) 443-451.

[21] V. Corinaldesi, G. Moriconi, Influence of mineral additions on the performance of $100 \%$ recycled aggregate concrete, Constr. Build. Mater. 23 (2009) 2869-2876.

[22] M. Gomes, J. de Brito, Structural concrete with incorporation of coarse recycled concrete and ceramic aggregates: durability performance, Mater. Struct. 42 (2009) 663-675. 
[23] J. Sim, C. Park, Compressive strength and resistance to chloride ion penetration and carbonation of recycled aggregate concrete with varying amount of fly ash and fine recycled aggregate, Waste Manage. 31 (2011) 2352-2360.

[24] C. Thomas, J. Setién, J. Polanco, P. Alaejos, M.S. De Juan, Durability of recycled aggregate concrete, Const. Build. Mater. 40 (2013) 1054-1065.

[25] S. Lotfi, M. Eggimann, E. Wagner, R.Mróz, J. Deja, Performance of recycled aggregate concrete based on a new concrete recycling technology, Constr. Build. Mater. 95 (2015) 243256.

[26] M. Bravo, J. de Brito, Pontes, L. Evangelista, Durability performance of concrete with recycled aggregates from construction and demolition waste plants, Constr. Build. Mater. 77 (2015) 357-369.

[27] R.V. Silva, R. Neves, J. De Brito, R.K Dhir, Carbonation behaviour of recycled aggregate concrete, Cem. Concr. Comp. 62 (2015) 22-32.

[28] D. Pedro, J. De Brito, L. Evangelista, Performance of concrete made with aggregates recycled from precasting industry waste: influence of the crushing process, Mater. Struct. 48 (2015) 3965-3978.

[29] EN 1097-6, Tests for mechanical and physical properties of aggregates. Determination of particle density and water absorption, CEN, Brussels (2013).

[30] EN 12390-3, Testing hardened concrete - Part 3: Compressive strength of test specimens, CEN, Brussels (2002)

[31] SN 505 262/1 Betonbau - Ergänzende Festlegungen, Anhang I,

Karbonatisierungswiderstand, SIA, Zürich, Switzerland (2013) (in French and German).

[32] A. Leemann, P. Nygaard, J. Kaufmann, R. Loser, Relation between carbonation resistance, mix design and exposure of mortar and concrete, Cem. Concr. Compos. 62 (2015) 33-43.

[33] A. Leemann, F. Moro, Carbonation of concrete: the role of $\mathrm{CO}_{2}$ concentration, relative humidity and CO2 buffer capacity, Mater. Struct. 50 (2017) 30.

[34] A. Leemann, R. Loser, B. Münch, P. Lura, Steady-state $\mathrm{O}_{2}$ and $\mathrm{CO}_{2}$ diffusion in carbonated mortars produced with blended cements, Mater. Struct. 50 (2017) 247.

[35] C.D. Lawrence, Transport of oxygen through concrete, in: Glasser, F.P. (ed), The chemistry and chemically-related properties of cement. British Ceramic Society Proceedings 35 (1984) 277-293.

[36] N.R. Buenfeld, E. Okundi, Effect of cement content on transport in concrete, Mag. Concr. Res. 50 (1998) 339-351.

[37] C. Villani, R. Loser, M.J. West, C. Di Bella, P. Lura, J.W. Weiss, An inter lab comparison of gas transport testing procedures: oxygen permeability and oxygen diffusivity, Cem. Concr. Compos. 53 (2014) 357-366.

[38] M. Wyrzykowski, P. Lura, F. Pesavento, D. Gawin, Modeling of water migration during internal curing with superabsorbent polymers, J. Mater. Civ. Eng. 24 (2011) 1006-1016.

[39] J. Justs, M. Wyrzykowski, F. Winnefeld, D. Bajare, P. Lura, Influence of superabsorbent polymers on hydration of cement pastes with low water-to-binder ratio, J. Therm. Anal.

Calorim. 115 (2014) 425-432.

[40] M. Wyrzykowski, P. Trtik, B. Münch, J. Weiss, P. Vontobel, P. Lura, Plastic shrinkage of mortars with shrinkage reducing admixture and lightweight aggregates studied by neutron tomography, Cem. Concr. Res. 73 (2015) 238-245. 
[41] D. Pedro, J. De Brito, L. Evangelista, Evaluation of high-performance concrete with recycled aggregates: Use of densified silica fume as cement replacement, Constr. Build. Mater. 147, (2017) 803-814.

[42] P. Amorim, J. De Brito, L. Evangelista, Concrete made with coarse concrete aggregate: influence of curing on durability, ACI Mater. J. 109 (2012) 195-204.

[43] F. P. Torgal, S. Miraldo, J.A. Labrincha, J. De Brito, An overview on concrete carbonation in the context of eco-efficient construction: Evaluation, use of SCMs and/or RAC, Constr. Build. Mater. 36 (2012) 141-150. 


\begin{tabular}{|c|c|c|c|c|c|c|c|c|c|c|c|c|c|c|}
\hline & $\mathrm{SiO}_{2}$ & $\mathrm{Al}_{2} \mathrm{O}_{3}$ & $\mathrm{Fe}_{2} \mathrm{O}_{3}$ & $\mathrm{Cr}_{2} \mathrm{O}_{3}$ & $\mathrm{MnO}$ & $\mathrm{TiO}_{2}$ & $\mathrm{P}_{2} \mathrm{O}_{5}$ & $\mathrm{CaO}$ & $\mathrm{MgO}$ & $\mathrm{K}_{2} \mathrm{O}$ & $\mathrm{Na}_{2} \mathrm{O}$ & $\mathrm{SO}_{3}$ & $\mathrm{LOI}$ & $\mathrm{TC}$ \\
\hline CEM II/A & 17.8 & 4.0 & 2.6 & 0.0 & 0.0 & 0.3 & 0.1 & 60.8 & 1.8 & 0.9 & 0.2 & 2.9 & 8.3 & 2.0 \\
\hline CEM II/B & 19.8 & 4.9 & 3.1 & 0.0 & 0.0 & 0.3 & 0.2 & 56.9 & 1.8 & 1.1 & 0.2 & 3.2 & 8.3 & 2.0 \\
\hline CEM III/B & 29.3 & 7.7 & 1.3 & 0.0 & 0.3 & 0.6 & 0.2 & 48.5 & 4.5 & 0.7 & 0.3 & 4.6 & 1.8 & 0.5 \\
\hline
\end{tabular}

Table 1: Chemical composition of the cements ( $\mathrm{LOI}=$ loss on ignition, $\mathrm{TC}=$ total carbon).

\begin{tabular}{|ll|c|c|c|c|}
\hline \multicolumn{2}{|c|}{} & \multicolumn{3}{|c|}{ RA-1 } & RA-2 \\
\hline grain size & {$[\mathrm{mm}]$} & $4 / 8$ & $8 / 16$ & $16 / 32$ & $4 / 16$ \\
\hline apparent particle density & {$\left[\mathrm{kg} / \mathrm{m}^{3}\right]$} & 2679 & 2691 & 2679 & 2718 \\
\hline oven-dried particle density & {$\left[\mathrm{kg} / \mathrm{m}^{3}\right]$} & 2397 & 2369 & 2427 & 2517 \\
\hline saturated surface-dry particle density & {$\left[\mathrm{kg} / \mathrm{m}^{3}\right]$} & 2503 & 2552 & 2.521 & 2591 \\
\hline water absorption & {$[\mathrm{mass}-\%]$} & 4.38 & 3.35 & 3.86 & 2.94 \\
\hline
\end{tabular}

Table 2: Particle density and water absorption of RA.

\begin{tabular}{|c|c|c|c|c|c|c|c|c|}
\hline mix & cement & $\begin{array}{c}\text { cement } \\
\text { content } \\
{\left[\mathrm{kg} / \mathrm{m}^{3}\right]}\end{array}$ & $w_{\text {total }} \mathrm{c}^{1}$ & $w_{E N} / \mathrm{c}^{2}$ & $\begin{array}{c}\text { SP } \\
{\left[\mathrm{kg} / \mathrm{m}^{3}\right]}\end{array}$ & $\begin{array}{c}\text { concrete } \\
\text { type }\end{array}$ & $\begin{array}{c}\text { RA } \\
{[\mathrm{mass}-\%]}\end{array}$ & $\begin{array}{c}\text { Aggregate } \\
\text { condition }\end{array}$ \\
\hline REF-01 & CEM II/A & 330 & 0.45 & 0.43 & 1.6 & $\mathrm{C}$ & - & dry \\
\hline REF-02 & CEM II/A & 310 & 0.50 & 0.48 & 0.6 & $\mathrm{C}$ & - & dry \\
\hline REF-03 & CEM II/A & 290 & 0.60 & 0.57 & - & B & - & dry \\
\hline REF-04 & CEM II/A & 280 & 0.65 & 0.62 & - & A & - & dry \\
\hline RC-01 & CEM II/A & 300 & 0.66 & 0.51 & - & B & 50 (RA-1) & dry \\
\hline RC-02 & CEM II/A & 300 & 0.66 & 0.51 & - & B & 50 (RA-1) & saturated \\
\hline RC-03 & CEM II/B & 300 & 0.66 & 0.51 & - & B & 50 (RA-1) & dry \\
\hline RC-04 & CEM II/A & 325 & 0.53 & 0.44 & 0.7 & C & 25 (RA-1) & dry \\
\hline RC-05 & CEM II/A & 325 & 0.53 & 0.44 & 0.7 & C & 25 (RA-1) & saturated \\
\hline RC-06 & CEM II/A & 325 & 0.57 & 0.43 & 1.3 & C & 50 (RA-1) & dry \\
\hline RC-07 & CEM II/A & 325 & 0.57 & 0.43 & 1.3 & C & 50 (RA-1) & saturated \\
\hline RC-08 & CEM II/A & 300 & 0.64 & 0.52 & 1.2 & B & 50 (RA-2) & dry \\
\hline RC-09 & CEM II/A & 300 & 0.64 & 0.52 & 1.2 & B & 50 (RA-2) & saturated \\
\hline RC-10 & CEM II/A & 325 & 0.54 & 0.42 & 3.4 & C & 50 (RA-2) & dry \\
\hline RC-11 & CEM II/A & 325 & 0.54 & 0.42 & 3.9 & C & 50 (RA-2) & saturated \\
\hline RC-12 & CEM II/B & 325 & 0.54 & 0.42 & 4.2 & C & 50 (RA-2) & dry \\
\hline RC-13 & CEM III/B & 325 & 0.51 & 0.42 & 1.6 & C & 25 (RA-1) & dry \\
\hline RC-14 & CEM III/B & 325 & 0.51 & 0.42 & 2.0 & C & 25 (RA-1) & saturated \\
\hline RC-15 & CEM III/B & 325 & 0.55 & 0.41 & 2.0 & C & 50 (RA-1) & dry \\
\hline RC-16 & CEM III/B & 325 & 0.55 & 0.40 & 2.0 & C & 50 (RA-1) & saturated \\
\hline RC-17 & CEM III/B & 410 & 0.48 & 0.38 & 6.2 & C & 50 (RA-1) & dry \\
\hline
\end{tabular}

${ }^{1} w_{\text {total }}=$ total water

${ }^{2} w_{E N}=$ total water subtracting the water adsorption of the aggregates as stated in Table 2 according to [2]

$\mathrm{SP}=$ superplasticizer

Table 3: Concrete mix design. 


\begin{tabular}{|c|c|c|c|c|c|c|c|c|c|c|}
\hline $\operatorname{mix}$ & air & $\rho$ & SF & $\mathrm{f}_{\mathrm{c}, 2 \mathrm{~d}}$ & $f_{c, 28 d}$ & $D_{o}$ & $K_{A C C}$ & $K_{A C C^{*}}$ & $K_{N, S}$ & $K_{N, U S}$ \\
\hline & {$[\%]$} & {$\left[\mathrm{kg} / \mathrm{m}^{3}\right]$} & {$[\mathrm{cm}]$} & \multicolumn{2}{|c|}{$[\mathrm{MPa}]$} & {$\left[10^{-8} \mathrm{~m}^{2} / \mathrm{s}\right]$} & \multicolumn{4}{|c|}{$\left[\mathrm{mm} / \mathrm{y}^{0.5}\right]$} \\
\hline REF-01 & 2.6 & 2384 & 35 & 26.1 & 43.6 & 2.1 & 2.3 & 2.8 & 5.8 & 3.1 \\
\hline REF-02 & 3.0 & 2363 & 36 & 21.7 & 36.6 & 2.4 & 2.8 & 2.7 & 5.2 & 2.7 \\
\hline REF-03 & 1.3 & 2394 & 48 & 14.4 & 30.6 & 3.3 & 4.2 & 4.4 & 3.8 & 1.1 \\
\hline REF-04 & 1.0 & 2407 & 51 & 12.0 & 27.8 & 3.3 & 5.2 & 5.1 & 1.2 & 0.1 \\
\hline RCA-01 & 1.7 & 2341 & 40 & 16.9 & 32.4 & 3.0 & 3.7 & 3.5 & 3.6 & 1.4 \\
\hline RCA-02 & 1.9 & 2344 & 41 & 17.8 & 33.5 & 2.8 & 3.8 & 3.8 & 4.0 & 1.3 \\
\hline RCA- 03 & 2.0 & 2319 & 40 & 20.1 & 37.1 & 3.0 & 4.4 & 4.8 & 4.6 & 2.2 \\
\hline RCA- 04 & 2.7 & 2368 & 38 & 21.7 & 37.0 & 2.6 & 2.6 & 3.2 & 3.2 & 1.0 \\
\hline RCA-05 & 1.6 & 2410 & 39 & 22.9 & 40.6 & 2.2 & 2.8 & 3.1 & 3.1 & 0.9 \\
\hline RCA-06 & 1.8 & 2366 & 39 & 22.3 & 43.3 & 2.0 & 2.9 & 3.4 & 3.4 & 0.8 \\
\hline RCA-07A & 1.5 & 2370 & 39 & 23.7 & 42.2 & 2.6 & 2.8 & 3.9 & 3.3 & 0.9 \\
\hline RCA-07B & 1.7 & 2329 & 42 & 22.7 & 41.1 & 2.2 & 2.9 & 3.3 & 3.2 & 1.2 \\
\hline RCA-08 & 2.4 & 2286 & 47 & 14.6 & 31.1 & 4.4 & 3.8 & 4.4 & 5.0 & 2.8 \\
\hline RCA-09 & 2.8 & 2308 & 36 & 15.1 & 31.5 & 4.2 & 4.2 & 4.4 & 4.7 & 2.3 \\
\hline RCA-10 & 1.7 & 2366 & 30 & 29.1 & 47.7 & 2.0 & 2.4 & 2.7 & 2.5 & 0.5 \\
\hline RCA-11 & 1.6 & 2375 & 35 & 30.6 & 51.1 & 1.7 & 2.3 & 2.9 & 2.1 & 0.5 \\
\hline RCA-12 & 2.0 & 2367 & 33 & 30.9 & 55.7 & 1.3 & 2.6 & 2.7 & 1.2 & 0.1 \\
\hline RCA-13 & 1.4 & 2379 & 46 & 13.0 & 50.0 & 0.6 & 4.4 & 4.3 & 6.3 & 2.0 \\
\hline RCA-14 & 1.4 & 2379 & 35 & 11.4 & 45.4 & 1.0 & 5.0 & 5.2 & 5.4 & 1.8 \\
\hline RCA-15 & 1.2 & 2364 & 35 & 11.7 & 47.9 & 0.5 & 4.6 & 5.1 & 5.2 & 1.5 \\
\hline RCA-16 & 1.5 & 2366 & 39 & 12.2 & 48.0 & 0.9 & 4.4 & 4.8 & 4.6 & 1.3 \\
\hline RCA-17 & 1.4 & 2373 & 56 & 17.0 & 66.5 & 0.8 & 3.0 & 3.4 & 2.1 & 0.3 \\
\hline
\end{tabular}

Table 4: Summary of the results ( $\operatorname{air}=$ air void content; $\rho=$ bulk density of the concrete; $\mathrm{SF}=$ slump flow; $\mathrm{f}_{\mathrm{c}, \mathrm{X}}=$ compressive strength at the age of $\mathrm{X}$ days; $D_{O}=\mathrm{O}_{2}$ diffusion coefficient; $K_{A C C}=$ carbonation coefficient in accelerated conditions; $K_{A C C^{*}}=$ carbonation coefficient in accelerated conditions taking into account locally increased carbonation depth due to RA; $K_{N, S}$ $=$ carbonation coefficient in sheltered exposure; $K_{N, U S}=$ carbonation coefficient in unsheltered exposure). 


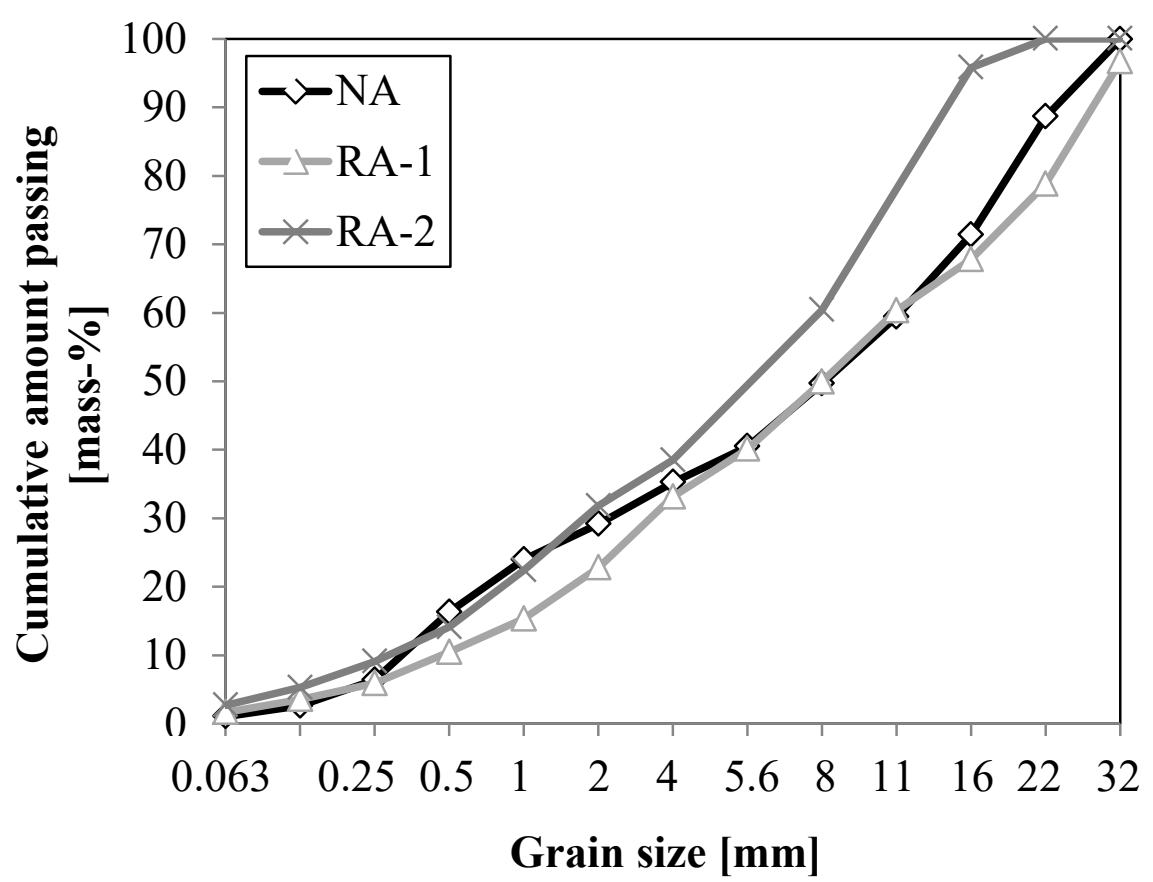

Figure 1: Grain size distribution of the aggregates. 


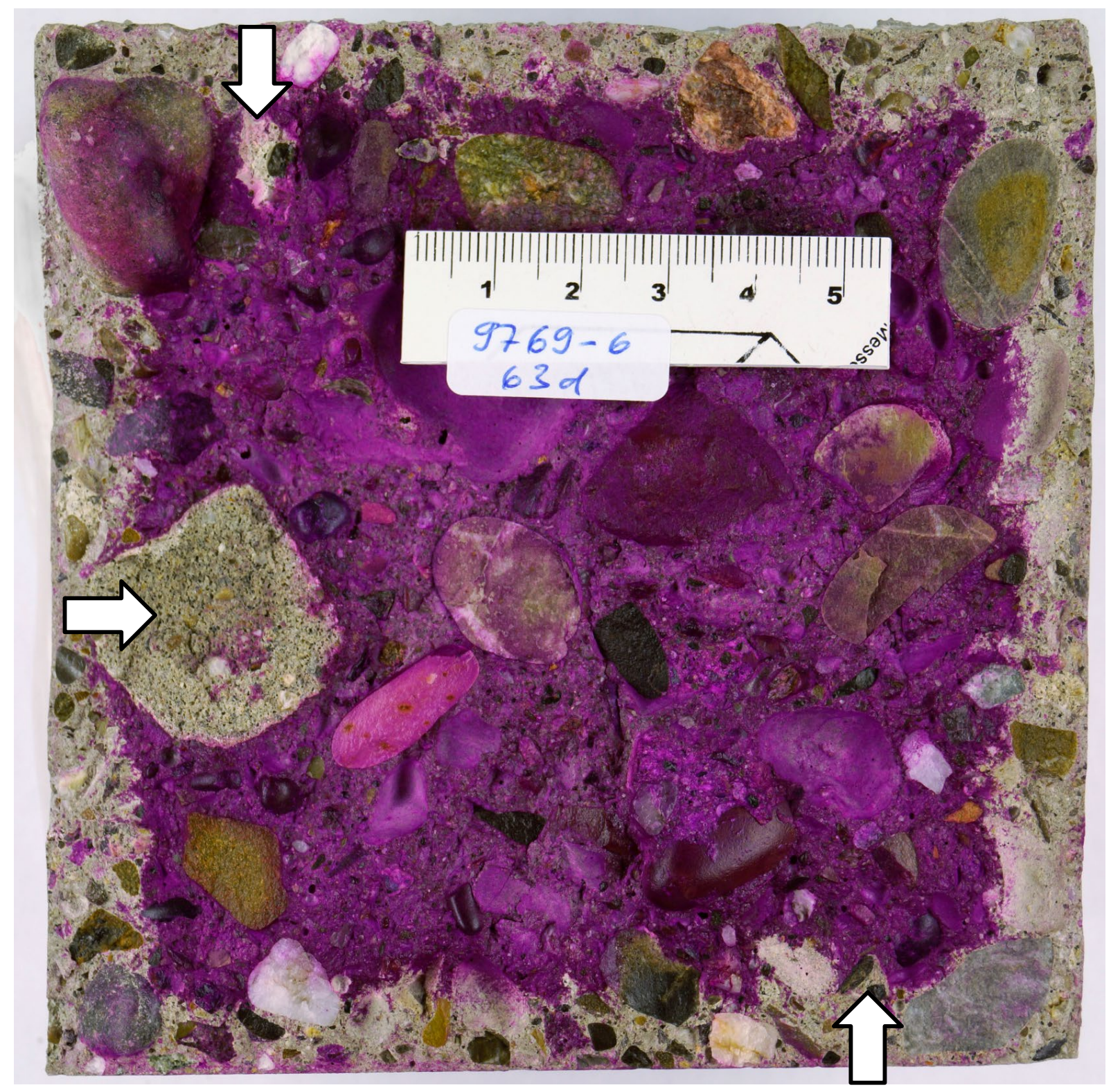

Figure 2: Surface of split concrete prism used in the carbonation test after being sprayed with phenolphthalein. The white arrows mark locations where RA leads to a locally-increased carbonation depth. 


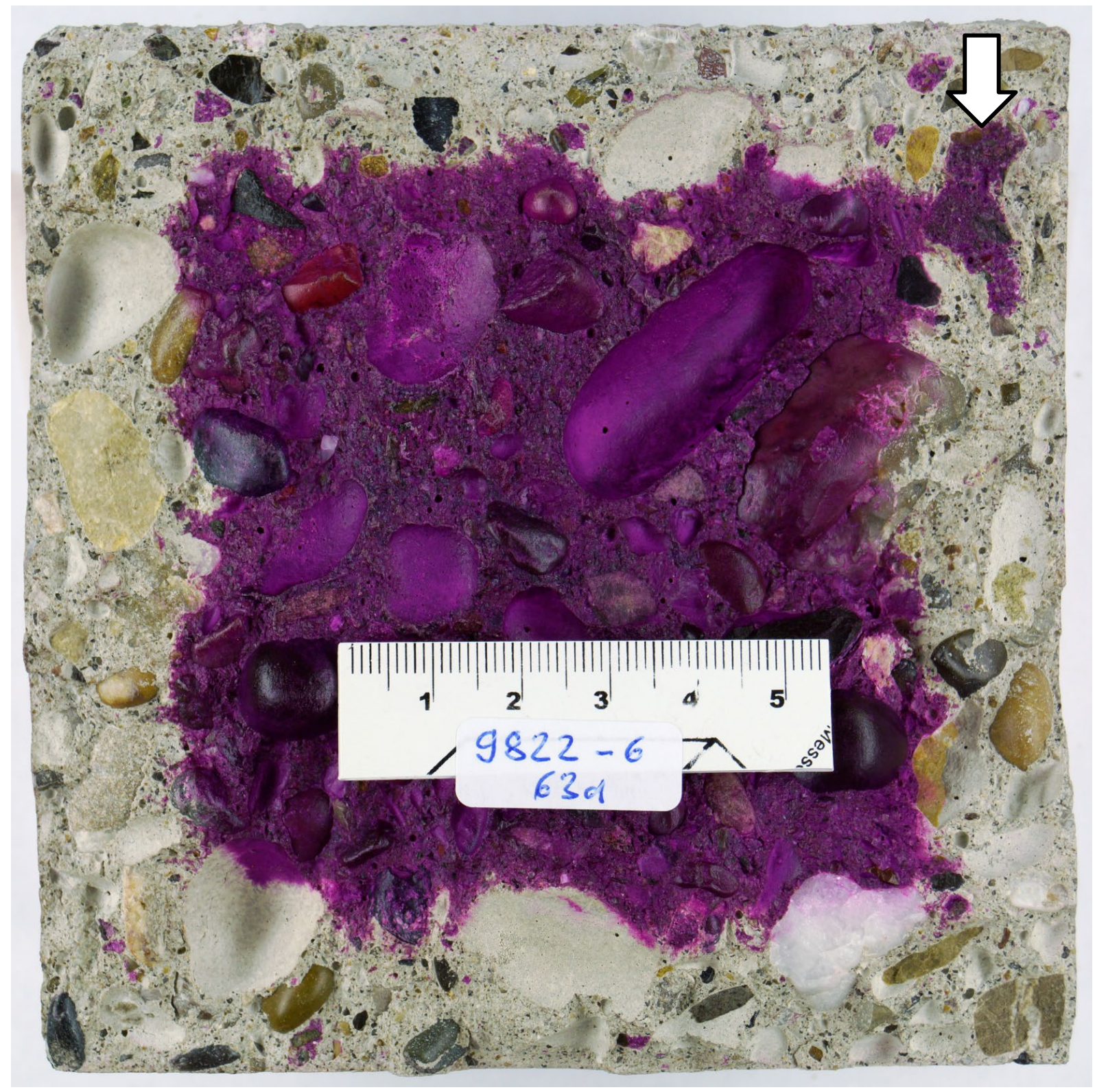

Figure 3: Surface of split concrete prism used in the carbonation test after being sprayed with phenolphthalein. The white arrow marks a location where RA leads to a locally-decreased carbonation depth. 

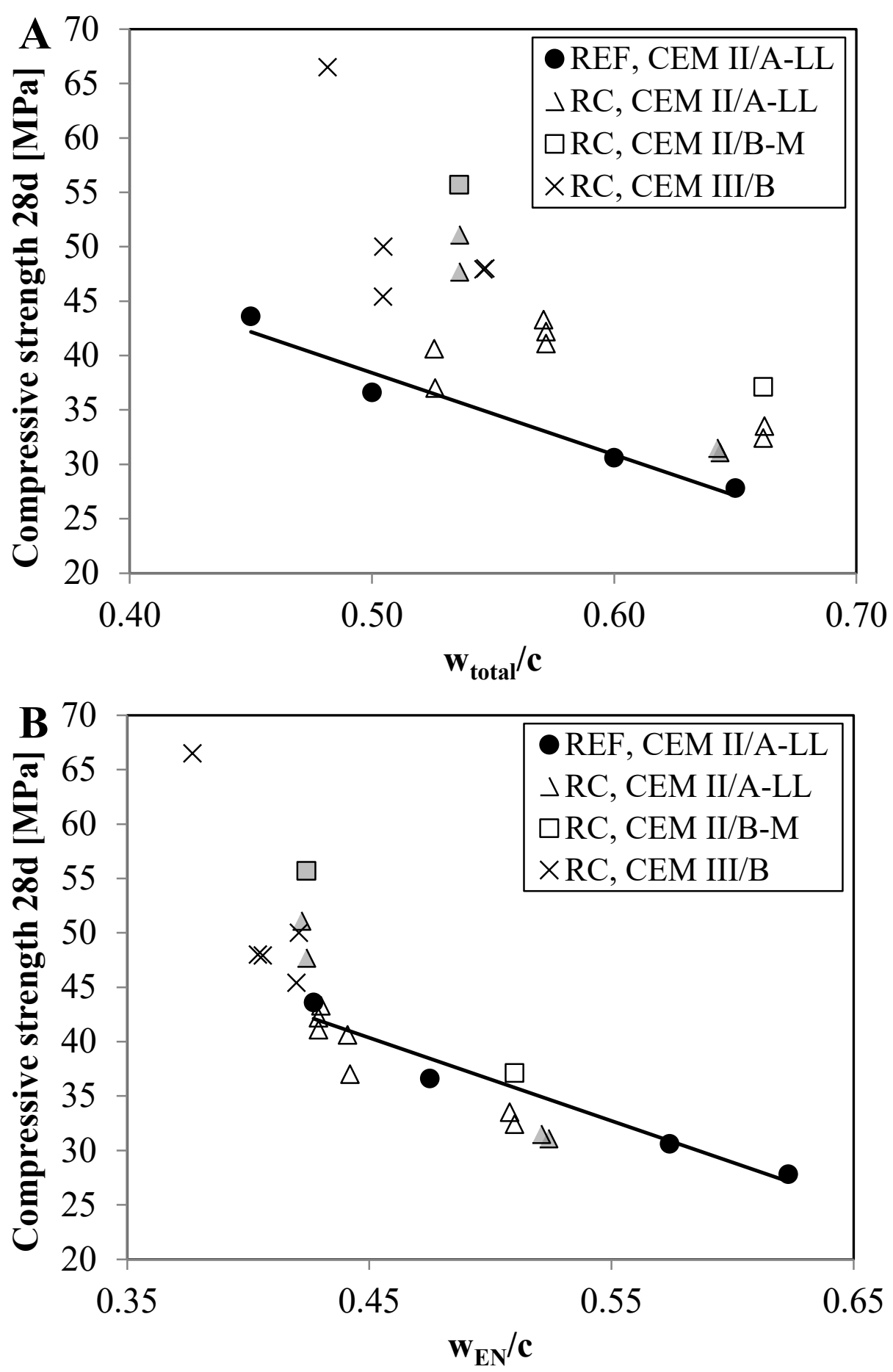

Figure 4: Compressive strength at 28 days as function of the $w_{t o t a l} / c(\mathrm{~A})$ and $w_{E N} / c$ (B). The line represents the regression of REF. The filled signs mark the concrete produced with RA-2. The line indicates the linear regression for concrete REF. 


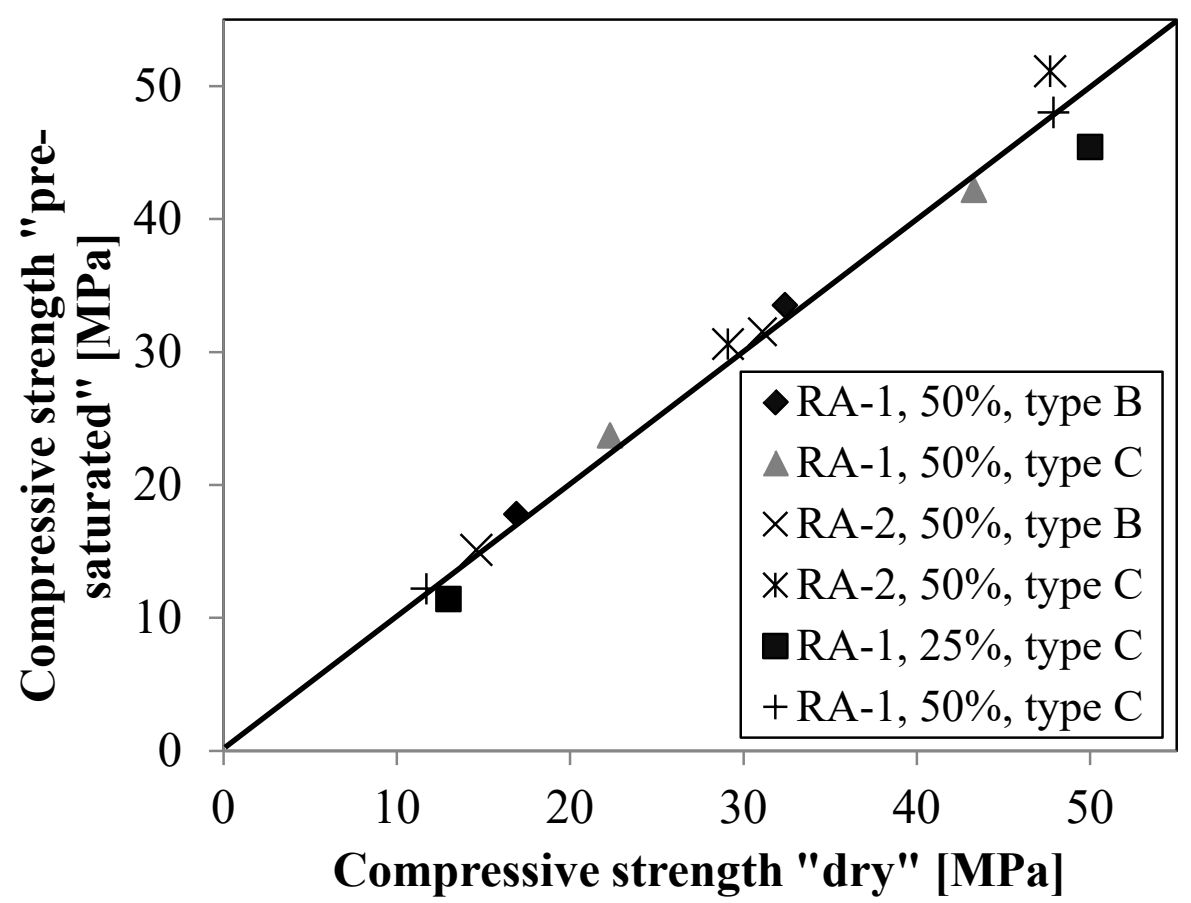

Figure 5: Compressive strength at 2 days (values $<30 \mathrm{MPa}$ ) and 28 days of concrete mixtures produced with dry aggregates compared to the values of concrete mixtures of identical mix design but the use of pre-saturated aggregates. The line indicates equality. 

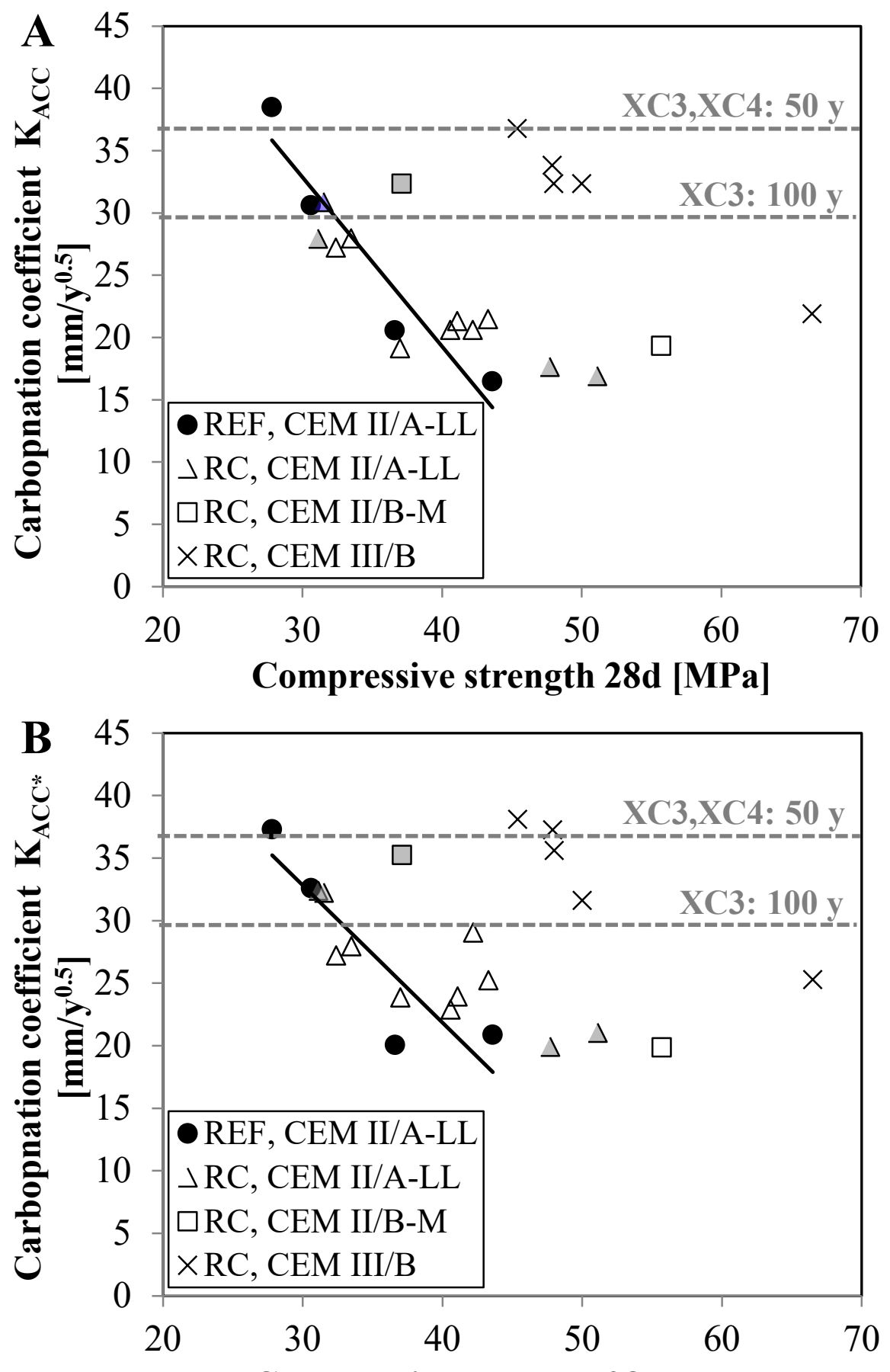

\section{Compressive strength 28d [MPa]}

Figure 6: Carbonation coefficient $K_{A C C}(\mathrm{~A})$ and carbonation coefficient $K_{A C C^{*}}(\mathrm{~B})$ as a function of compressive strength at 28 days. Limit values of carbonation coefficient $K_{A C C}$ depending on exposure class and planned service life according to [2]. The line indicates the linear regression for concrete REF. 


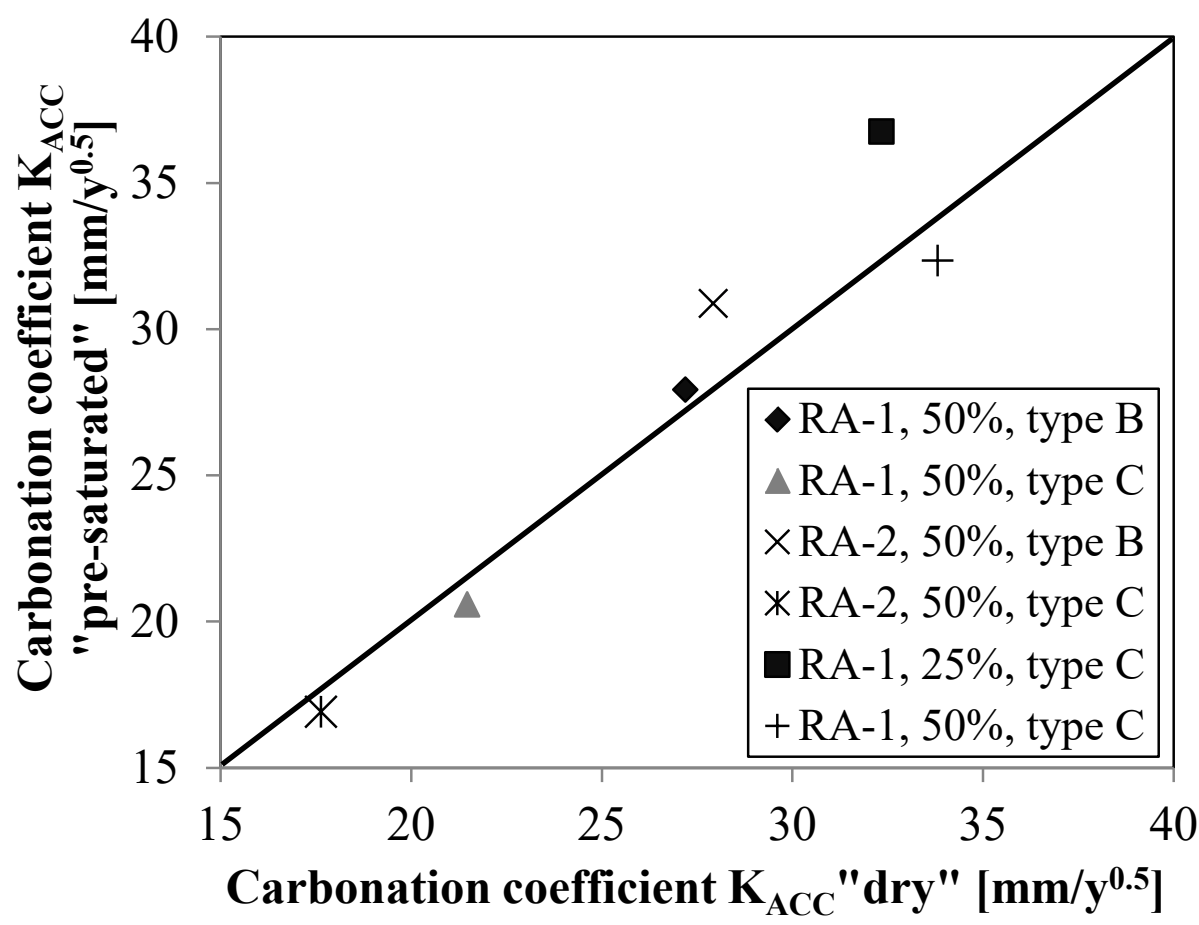

Figure 7: Carbonation coefficient $K_{A C C}$ of concrete mixtures produced with dry aggregates compared to the values of concrete mixtures of identical mix design but the use of pre-saturated aggregates. The line indicates equality. 

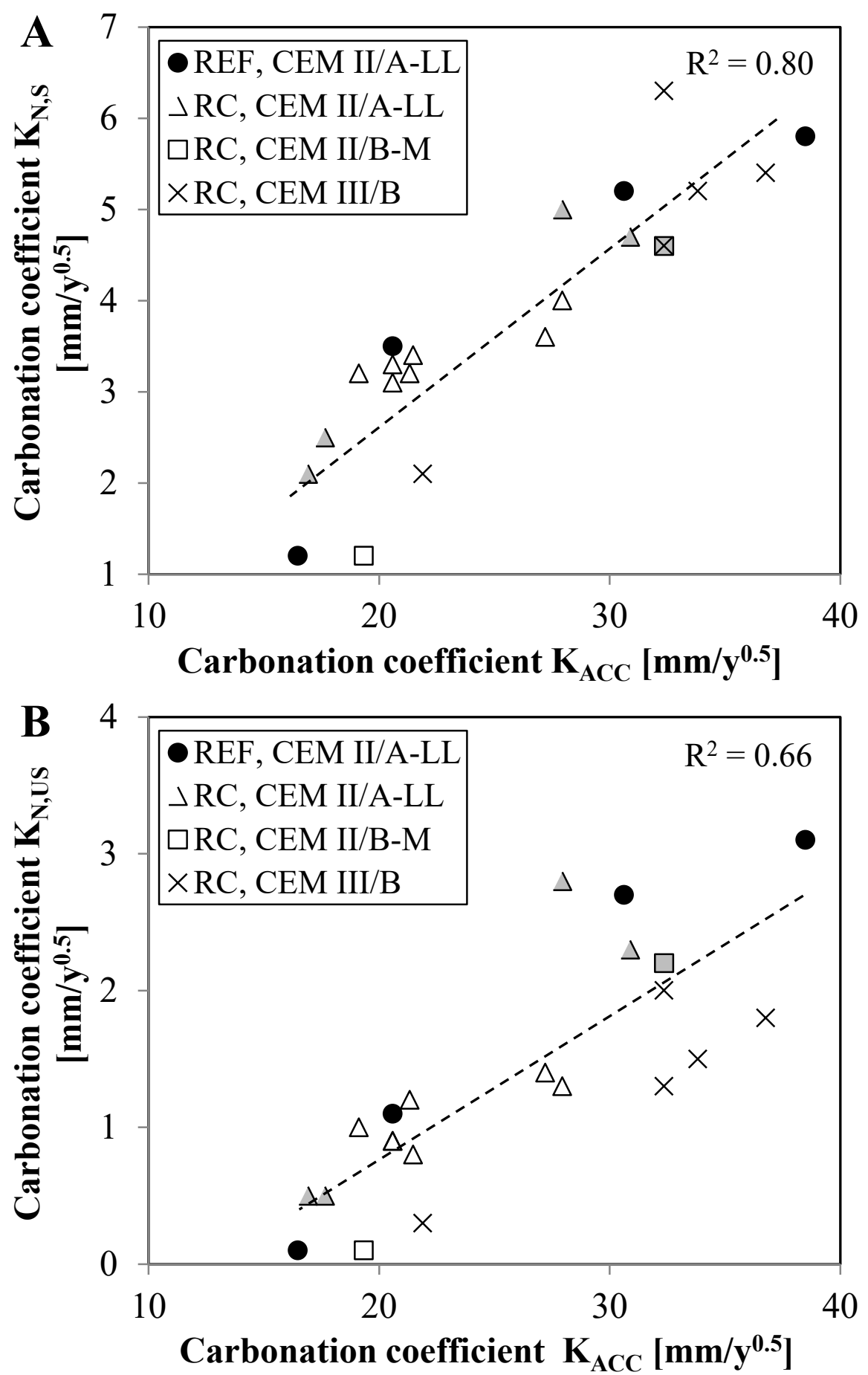

Figure 8: Carbonation coefficient $K_{N, S}$ in sheltered (A) and $K_{N, U S}$ in unsheltered outdoor exposure (B) as a function of carbonation coefficient $K_{A C C}$ in accelerated conditions. The line indicates the linear regression for all concrete mixtures. 


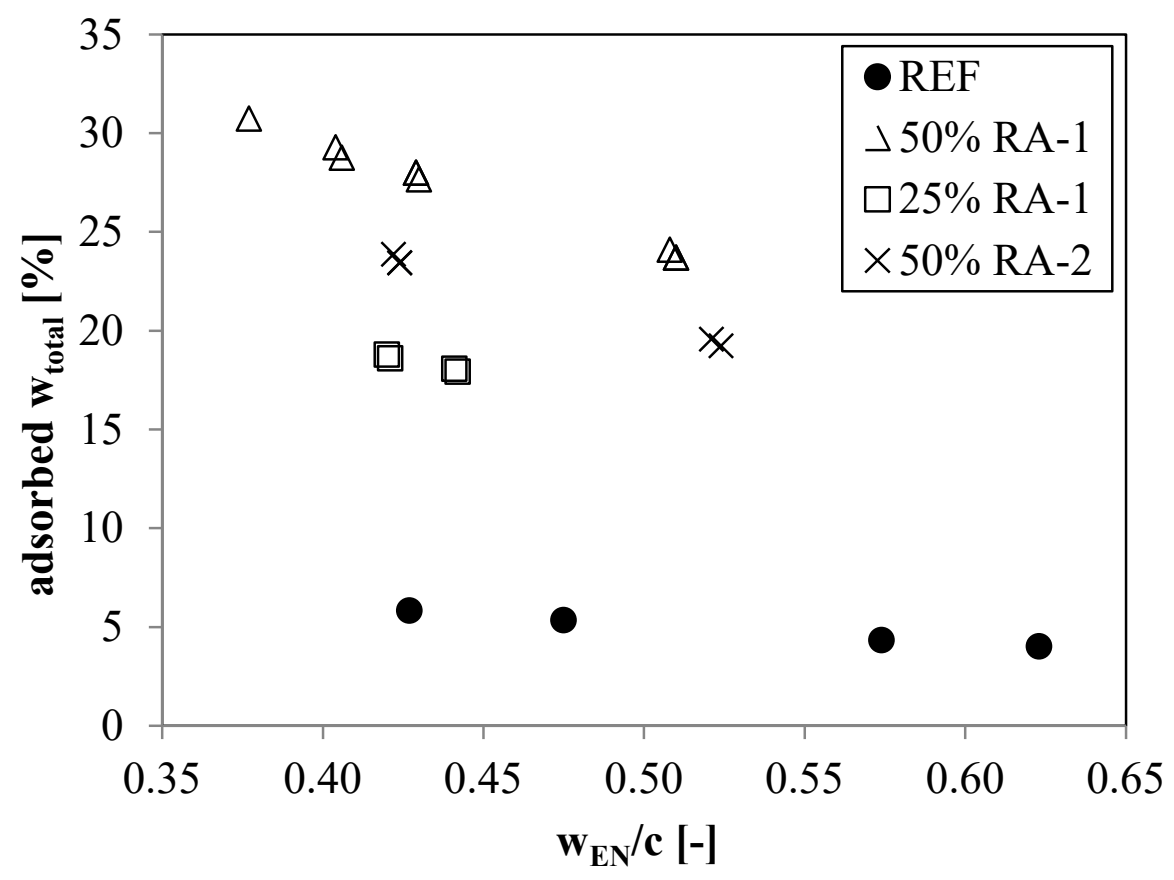

Figure 9: Percentage of total water absorbed by the aggregates in the different concrete mixtures as a function of $w_{E N} / c$. 